\title{
Influence of alkyl chain length in ionic liquid based drilling mud for rheology modification: a review
}

\author{
Asif Zamir ${ }^{1} \cdot$ Khaled A. Elraies ${ }^{1} \cdot$ Muhammad Hammad Rasool $^{1} \cdot$ Maqsood Ahmad $^{1} \cdot$ Muhammad Ayoub $^{2}$. \\ Muhammad Adeem Abbas ${ }^{1} \cdot$ Imtiaz Ali $^{1}$
}

Received: 29 July 2021 / Accepted: 17 October 2021 / Published online: 25 October 2021

(C) The Author(s) 2021

\begin{abstract}
The research has shown successful application of ionic liquids (ILs) as drilling fluid additives for modifying the mud rheology. Ionic liquids are tuneable solvents comprising of hundreds of combination of various cations and anions. The cationic portion mainly comprises of a side alkyl chain which plays an important role in altering the drilling fluid properties. This review mainly focusses on finding the impact of alkyl chain length on yield point, plastic viscosity and filtration properties of water based mud at room temperature. The paper also incorporates the X-ray diffraction (XRD) analysis carried out on various ionic liquids by different research groups which confirms how the intercalation between ionic liquid and Na-Bt (Sodium Bentonite) changes the structure of clay and thus alters the rheology of the mud. It can be concluded that ionic liquids act as rheology modifiers by intercalating between the clay layers and thus changing the d-spacing of the clay. Moreover, the hydrophobicity, polarity and solubility of alkyl chain play an important role in altering the wettability and dispersion behavior of clay which modify the filtration as well as rheological properties of the mud.
\end{abstract}

Keywords Ionic liquids $\cdot$ Rheology $\cdot$ Drilling fluid

\section{Introduction}

In carrying a successful and optimized drilling operation, the most crucial factor is the design of the drilling mud (Junqueira et al. 2003; Barton 2014). Drilling fluid can primarily be categorized on the base of continuous phase to oil-based and water-based drilling muds (Herzhaft et al. 2001). However, the application of air-based drilling fluid is very rare (Guangchang 2004; Hamed and Belhadri 2009). Numerous additives are used in the drilling mud formation to improve the mud rheology and filtrate control (Ekeinde et al. 2019; Zamir et al. 2021). The most notable additives are watersoluble polymers, starch, different low-solids, xanthan gum, non-dispersed polymer systems (Srivatsa and Ziaja 2011). But the problem with polymers are that they are degradable

Asif Zamir

asif.zamir@utp.edu.my

1 Petroleum Engineering Department, Universiti Teknologi PETRONAS, Bandar Seri Iskandar, Perak, Malaysia

2 Chemical Engineering Department, Universiti Teknologi PETRONAS, Bandar Seri Iskandar, Perak, Malaysia at high temperature thus rendering the drilling fluid unstable at elevated temperatures (Halliday and Thielen 1987).

Oil-based drilling mud has certain benefits as in good thermal stability and excellent cutting carry ability but their synthesis is costly and the dumping causes a lot of environmental hazards, i.e., water table contamination, soil contamination, and air contamination (Van Slyke 1994; Patel 2001; Patel et al. 2007). So, generally water-based mud is mostly preferred due to less environmental footprints, and various additives are added to tune the mud properties according to the requirements (Elmquist and Boesger 1987; Kjøsnes et al. 2003).

Drilling mud performs a number of functions which include the hydraulic pressure to stop formation fluids influx, suspension, removal and transportation of the cuttings from the borehole, cooling and lubrication of the drill string and drill bit and providing buoyancy to the drill string (Ahmed and Makwashi 2016; Najem et al. 2019). The drilling mud should be designed in a way that the drilling fluid will alter the mechanical properties of the formation as least as possible (Sudakov et al. 2016). Different additives change the mud rheology in different ways, whereas rheology is the study of viscoelastic liquids and solids in which they 
undergo through a plastic deformation rather than elastic deformation when are combated with stress (Coussot 2017; Phan-Thien and Mai-Duy 2017).

Rheology generally deals with the non-Newtonian fluids such as drilling mud which shows shear thinning behavior (Kulkarni et al. 2019; Welahettige et al. 2019). Shear thinning is a behavior in which the viscosity of fluid decreases under shear strain (Zhu et al. 2015). When the drilling mud is flowing through drill string, low viscosity is needed for easy circulation but when it passes through the annulus with cuttings, high viscosity is expected for the effective suspension and transportation of the cuttings (Morenov and Leusheva 2017) (Anoop et al. 2019). Therefore, shear thinning behavior is recommended for the drilling fluids (Hong et al. 2019).

The shear thinning behavior of drilling fluids and cutting transport capability can be characterized by YP/PV ratio (Chilingarian et al. 1986). In previous studies, it was observed that drilling fluids with very low YP/PV failed to transport cuttings and clean the wellbore, while drilling fluids with high YP/PV offered worse drilling hydraulics and overloaded the circulating system of drilling fluids (Huaike and Xuebin 2010; Darley et al. 2011). The YP/PV values in the limit from 0.36 to $0.48(\mathrm{~Pa} / \mathrm{mPa} . \mathrm{s})$ are more appropriate because in that case the drilling fluids can transport the cuttings and clean the wellbore more efficiently (Okrajni and Azar 1986; Okon et al. 2015).

Lately, ionic liquids due to their various applications are being used as a drilling fluid additives as rheology modifiers (Luo et al. 2017a, b). ILs are organic salts that remain in liquid state at room temperature retaining high thermal stability as compared traditional additives, no vapor pressure and greener nature (Luo et al. 2017a, b). Many researchers are utilizing the application of ionic liquids as a drilling fluid additive for improving the mud rheology.

The survey on the literature of the utilization of Ionic liquid as a drilling fluid additive for rheology modifier has led to the conclusion there is not much work done particularly in this domain. However, in this paper, application of ionic liquid as a function of its alkyl chain length for WBM (water-based mud) has been reviewed from the very limited literature available.

\section{Structure of the review paper}

The "Drilling mud rheology" section sheds lights on the drilling mud rheology and its significance in general. "Ionic liquids" section will focus on the chemistry of ionic liquids. "Ionic liquids as drilling fluid additives" section will discuss in detail the effect of alkyl chain length of ionic liquids (as a drilling fluid additive) on yield point, plastic viscosity and filtration properties of the drilling mud. Lastly, "Effect of iconic liquid on d-spacing of drilling mud" section discusses the effect of ionic liquid on d-spacing of drilling mud.

\section{Drilling mud rheology}

Drilling fluid design is very significant in customizing the drilling fluid rheology. The knowledge of yield point and plastic viscosity is important in drilling hydraulics calculation as they play a vital role in cutting transportation phenomenon of the drilling mud. Yield point is simply the internal resistance of the fluid to flow which is measured in $\mathrm{lbm} / 100 \mathrm{ft}^{2}$ (Zamir et al. 2021). Plastic viscosity is the measure of the solid content present in the drilling mud which is measured in centipoise (cp). The drilling fluids are designed in such a way to keep the plastic viscosity as low as possible (Zamir et al. 2021).

\section{Ionic liquids}

Ionic liquids are the liquid salts that exist in liquid state at room temperature. They are mainly composed of a cation and an anionic portion. Cationic portion is mainly organic while inorganic entity can be organic, as well as inorganic. Ionic liquids are mainly held together by dispersive electrostatic force of attraction which gives it a special nonisotropic character (Welton 2018). There is vast diversity of species which make up the cationic portion of the ionic liquids, e.g., azoliums such as imidazolium, pyridinium, and phosphonium. Similarly, anionic portion is mainly held by halides or organic anions such as alkylcarbonates and alkylsulfates. Due to these variety of choices, there are thousands of combination of ionic liquids which can be used. This the reason that ionic liquids are termed as tunable solvent whose properties can be customized by playing with the cationic or anionic portion of the ionic liquid (Singh and Savoy 2020).

\section{Ionic liquids as drilling fluid additives}

Ionic liquids, due to their versatile nature and electrostatic behavior, are lately used as drilling fluid additives. There has not been much done in this area but it is about time that field applications of ionic liquids in drilling industry will be exploited.

In this paper, from the limited available literature, a systematic analysis is carried out to observe the effect of ionic liquids on the rheological and filtration properties of the drilling mud. Table 1 shows different ionic liquids which have been used as drilling fluid additives.

A detailed summary of drilling fluid composition, mud rheology values and type of muds used by the reported 
Table 1 Ionic liquids as drilling fluid additives in water-based mud

\begin{tabular}{|c|c|c|c|c|c|}
\hline Author & Ionic liquid & Alkyl chain length & Concentration (\%) & Pressure (psia) & Temperature ${ }^{\circ} \mathrm{C}$ \\
\hline $\begin{array}{l}\text { Tinku Saikia et al. (Saikia and } \\
\text { Mahto 2016) }\end{array}$ & $\begin{array}{l}\text { 1-Decyl-3-Methylimidazo- } \\
\text { lium Tetrafluoroborate }\end{array}$ & Long & $0.1,0.5 .1 .0$ & Atmospheric & 2 and 20 \\
\hline $\begin{array}{l}\text { Zhihua Luoa et al. (Pei et al. } \\
\text { 2017) }\end{array}$ & $\begin{array}{l}\text { 1-octyl-3-methylimidazolium } \\
\text { tetrafluoroborate }\end{array}$ & Long & 0.05 & $\mathrm{x}$ & $25-160$ \\
\hline $\begin{array}{l}\text { Titus Ntow Ofei et al. (Bavoh } \\
\text { et al. 2017) }\end{array}$ & $\begin{array}{l}\text { 1-butyl-3-methylimidazolium } \\
\text { chloride }\end{array}$ & Short & $3 \%$ w.r.t. mass of water & 1000 & $25-200$ \\
\hline $\begin{array}{l}\text { Luo Zhihua Song Bingqiang } \\
\text { (Wang et al. 2017) }\end{array}$ & $\begin{array}{l}\text { 1-dodecyl-3-methylimidazo- } \\
\text { lium chloride }\end{array}$ & Long & $0.05 \%$ & $\mathrm{x}$ & $25-160$ \\
\hline $\begin{array}{l}\text { Cornelius et al. (a) (Bavoh, } \\
\text { Ofei et al. 2019) }\end{array}$ & $\begin{array}{l}\text { 1-methyl-3-octylimidazolium } \\
\text { tetrafluoroborate }\end{array}$ & Long & $1 \%$ & $\mathrm{x}$ & -2 to 70 \\
\hline $\begin{array}{l}\text { Arvind et al. (Thaemlitz et al. } \\
\text { 1999) }\end{array}$ & $\begin{array}{l}\text { Triethanolamine-methyl } \\
\text { chloride condensates }\end{array}$ & Short but branched & $8 \mathrm{ml}(1.89 \%)$ & $\mathrm{x}$ & $25-160$ \\
\hline $\begin{array}{l}\text { Cornelius et al. (b) (Partoon } \\
\text { et al. 2016) }\end{array}$ & $\begin{array}{l}\text { 1-Ethyl-3-methylimidazolium } \\
\text { chloride }\end{array}$ & Short & $1,2,3$ & $\mathrm{x}$ & $\mathrm{x}$ \\
\hline (Ahmed Khan et al. 2020) & $\begin{array}{l}\text { 1-allyl-3- methyllimidozium } \\
\text { iodide }\end{array}$ & Short but unsaturated & $\mathrm{x}$ & $\mathrm{x}$ & 25 \\
\hline
\end{tabular}

investigators can be read in our previous work (Rasool et al. 2021a, b).

\section{Impact of ionic liquids on mud rheology and its filtration properties}

Ionic liquids are composed of a cation and anion. The cationic portion is mainly the alkyl chain whose length plays a significant role in changing the properties of drilling fluid. The alkyl chain length can be changed to customize the properties of the drilling.

Tinku et al. worked on hydration inhibition by using an ionic liquid hence he considered the marine conditions $\left(2^{\circ}\right.$ and $\left.20^{\circ} \mathrm{C}\right)$ for the study of the rheology. Zhihua et al. mainly focused on studying rheological and filtration properties of ionic liquid-based mud for high-temperature wells. They also compared the YP/PV ratio of all mud samples. Titus et al. studied the performance of ionic liquid (BMIMCl) for HT wells. They also applied different models to figure out the best fit model to describe the rheological properties of the mud they were using. Luo Zhihua Song Bingqiang has a patent for devising a heterocyclics ionic liquid-based drilling fluid which they claimed to be useful for temperature inhibitive performance with lesser filtration loss and improved rheology. Cornelius et al. studied the rheology properties and hydration inhibition traits of xanthan gum and PAS-based mud with and without using the ionic liquid. He chose the temperature range of $-2^{\circ}$ to $70^{\circ} \mathrm{C}$ because it represents the typical hydrates bearing sediments environment. In following sections, from the reported literature, the effect of alkyl chain length on the behavior drilling mud has been analyzed.

\section{Analysis of the effect of alkyl chain length on yield point and plastic viscosity}

Yield point is an important parameter in drilling mud rheology. The high value of yield stress is needed so that the mud can hold and transport the cuttings effectively. At the same time, very high values of yield stress will result in excessive pressure drop and increase in equivalent circulation density.

Similarly, in drilling fluid designing process, it is made sure to keep the plastic viscosity as low as possible. Ionic liquids have the ability to directly affect the yield point and plastic viscosity of the drilling fluid.

Figures 1 and 2 show the impact of alkyl chain on mud rheology in water-based drilling mud. The comparison is drawn using Table 1 choosing the ionic liquids which have been used in same mud formulation with the same type of anion. The exact numerical values might not be helpful in drawing a rational conclusion; however, this comparison

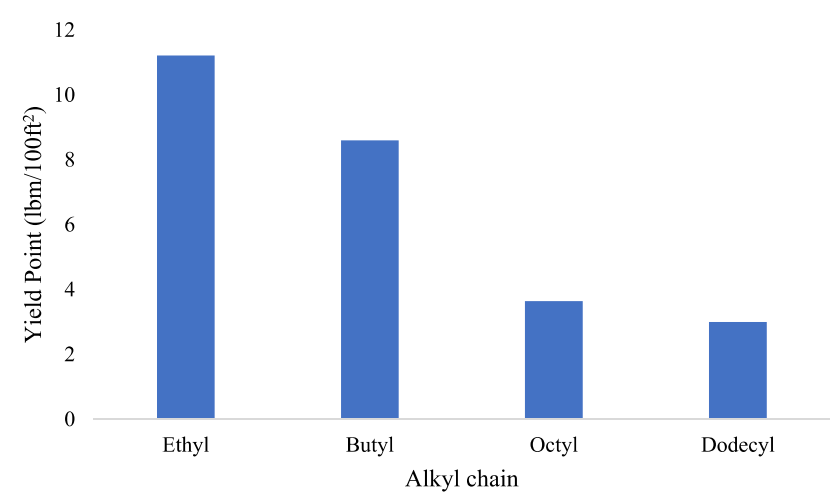

Fig. 1 Effect of alkyl chain length of ILs on YP 


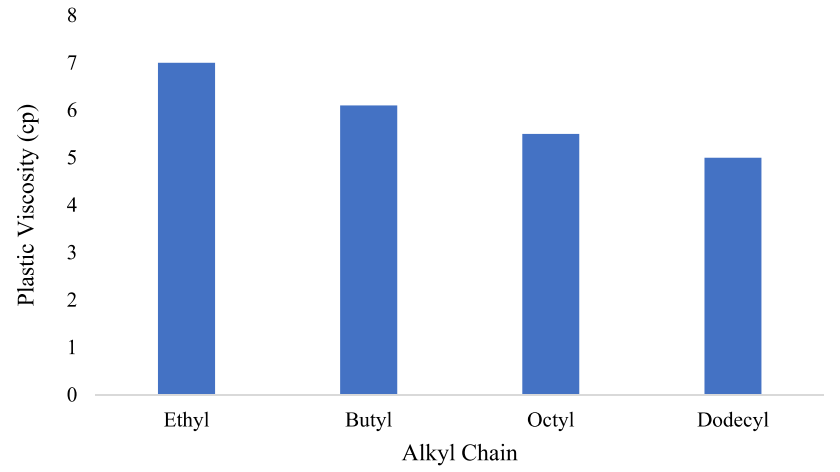

Fig. 2 Effect of alkyl chain length of ILs on PV

helps in identifying the general trend of role of alkyl chain length.

The high viscosity in sodium bentonite suspension is caused by its edge-to-face interaction between the positively charged edge and the negatively charged flat surface forming an arrangement like 'house-of-cards' as shown in Fig. 3.

From Figs. 1 and 2, it can be seen that longer alkyl chain will result into lesser values of yield point and plastic viscosity.

The longer alkyl chain causes lesser polarity and more hydrophobicity in contrast to small chain alkyl which induces higher polarity in medium. The longer alkyl chain will have larger surface area and being the cationic portion of the ionic liquid, it will attach to the negatively charged surface of sodium bentonite due to electrostatic interaction and hydrophobicity. This interaction will prevent the attraction between face to edge orientation of sodium bentonite which will eventually take down the microstructure of sodium bentonite (Na-Bt) causing low values of YP and PV (Yang et al. 2019).

It is always recommended to study yield point (YP) and plastic viscosities (PV) as ratio, i.e., YP/PV because it is more logical to model their combined effect. The more discussion on the effect of ionic liquid on YP/PV can be found in our previous work (Zamir et al. 2021).

\section{Analysis of the effect of alkyl chain length on filtration properties}

The analysis of the effect of alkyl chain on filtration properties of mud is drawn using Table 1 and can be seen in Figs. 4 and 5.

From Figs. 4 and 5, it can be seen that longer alkyl chain results into improved filtration properties. Allyls are unsaturated hydrocarbons and they perform worse than saturated hydrocarbons. The longer alkyl chain shows better filtration properties because the longer alkyl chain length has more molecular mass occupying more volume and surface area and has less hydrophilicity and solubility which alters the wettability of the clay which in turns alters its filtration properties.

\section{Hydrophobicity of ionic liquids}

Hydrophobicity is an important parameter in understanding the mechanism of ionic liquids as rheology modifiers. Hydrophobicity of ionic liquids can be changed by choosing a different type of cation for the formation of ionic liquids. The longer the alkyl chain is, the higher will be the hydrophobicity (Huddleston et al. 2001).

This hydrophobicity helps in changing the wettability of clay and expel water from alumino-silicate layers in sodium bentonite (clay) which improves the filtration properties, as well as the rheology of the mud (Yang et al. 2019).

\section{Polarity of ionic liquids}

Polarity is another important factor in understanding the underling mechanism behind the working of ionic liquids

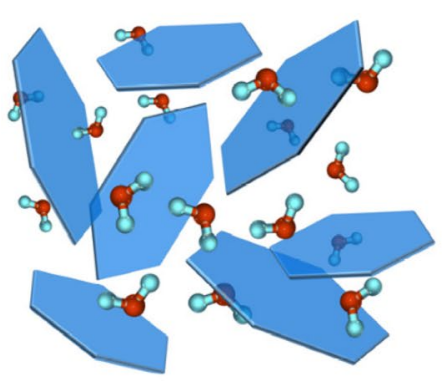

Dispersed

(a)

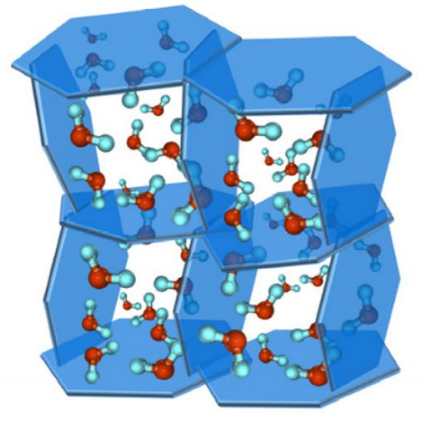

Edge-Face

(b)

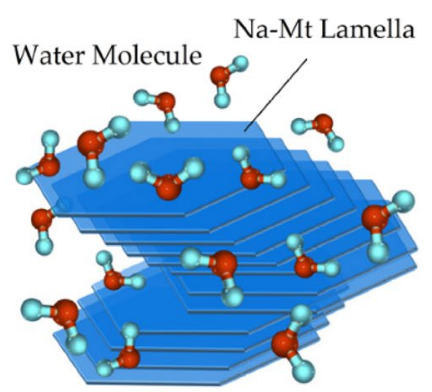

Face-Face

(c)

Fig. 3 Dispersed and face to edge orientation of Na-Bt (Li et al. 2020) 

in mudcake thickness as a function of alkyl chain length of ILs
Fig. 4 Improvement (reduction)

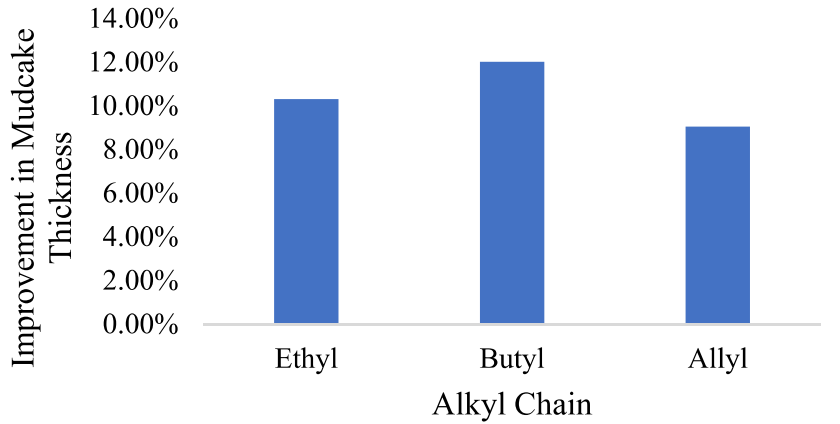

Hydrophobicity-polarity dilemma

Hydrophobicity in ionic liquids is desirable because it helps the interaction and intercalation between sodium bentonite and ionic liquids. At the same time, polarity plays an important role in creating an electrostatic interaction between cay and ionic liquids. It is observed that longer side chain alkyls groups are more hydrophobic but induces less polarity in the medium. This dilemma can be resolved by the tuneable nature of ionic liquids. Such ionic liquids are available which are polar, as well as hydrophobic, thus presenting an ideal drilling fluid additive for improving drilling fluid properties (Fukaya and Ohno 2013).

chain length of ILs

as drilling fluid additives. Alkyl groups are non-polar due to symmetrical arrangement of $\mathrm{C}-\mathrm{H}$ bond and negligible electronegativity difference between $\mathrm{C}$ and $\mathrm{H}$. However, in ionic liquids, the length of side chain alkyl groups affects the polarity of ionic liquids slightly (Lee and Prausnitz 2010; Hayes et al. 2014). The smaller alkyl chains cause more polarity but lesser hydrophobicity (Voelkel et al. 1988; Bogdanov et al. 2010). This higher polarity will result into a more successful electrostatic interaction between clay and Ionic liquids which will change the dispersion behavior of the clay. But at the same time, hydrophilic ionic liquids may not successfully intercalate between alumino-silicate layers and expel water out of it.

\section{Solubility of ionic liquids}

The shorter alkyl chain length Ionic liquids (C2-C4) are readily soluble in water but as the alkyl chain length (C6-C8) increases, the aqueous solution turns cloudy. The solubility becomes difficult as the alkyl chain length keeps on increasing. The longer chain ionic liquids possess a certain degree of self-organization which makes its solubility difficult in water (Kurnia et al. 2015).

\section{Effect of ionic liquid on d-spacing of drilling mud}

This section discusses the underlying mechanism behind the interaction between ionic liquids and sodium bentonite/ montmorillonite. Na-Bt has the tendency to adsorb ionic liquid into its layer which govern the swelling characteristics of clay and in turn alter the rheology of the mud. Following paragraphs summarize the previous work done in understanding the interaction between clay and ionic liquids and how the ionic exchange enhances the mud rheology.

Ren et al. (2019) studied the adsorption effect of imidazolium-based ionic liquids on sodium bentonite. This research group focused on four ionic liquids 1-ethyl-3-methylimidazolium chloride, 1-butyl-3-methylimidazolium chloride, 1-aminoethyl-3-methylimidazolium and 1-hydroxyethyl3-methylimidazolium chloride on the basis of their tendency to inhibit Na-Bt hydrates swelling. They found out that the dependence of low shear rate viscosity on IL's structure and concentration gave the idea that gel strength of the drilling fluid might be influenced by the structure and concentration of ILs. They conclude that the cationic group of ionic liquid adsorbed onto the $\mathrm{Na}-\mathrm{Bt}$ before the water molecules, which expelled the water and compressed the layers of $\mathrm{Na}-\mathrm{Bt}$, which in turn inhibited the swelling (Wang et al. 2019).

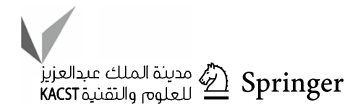


Table 2 d-spacing analysis of Dry Na-Bt and Na-Bt modified with ILs

\begin{tabular}{|c|c|c|c|c|}
\hline Research group & Ionic liquid & Optimum concentration & $\begin{array}{l}\mathrm{D}_{001} \text { blank sam- } \\
\text { ple } \mathrm{A}^{\circ} \text { (Dried) }\end{array}$ & $\begin{array}{l}\mathrm{D}_{001} \text { ionic } \\
\text { liquid modified } \\
\mathrm{A}^{\circ}\end{array}$ \\
\hline \multirow[t]{5}{*}{ Reinert et al } & $\mathrm{AMImCl}$ & \multirow[t]{5}{*}{ Not provided } & \multirow[t]{5}{*}{12.13} & 12.80 \\
\hline & $\mathrm{BMImCl}$ & & & 13.69 \\
\hline & $\mathrm{OMImCl}$ & & & 13.80 \\
\hline & $\mathrm{BPyBr}$ & & & 13.59 \\
\hline & OpyBr & & & 13.91 \\
\hline Jingjing Pei et al & 1-butyl-3-methylimidazolium tetrafluoroborate & $200 \mathrm{mg} / \mathrm{L}$ & 12.3 & 14.24 \\
\hline XiaolongWang et al & 1-hexadecyl-3-methylimidazoliumchloridemonohydrate & $100 \mathrm{mg} / \mathrm{L}$ & 12.63 & 20.88 \\
\hline \multirow[t]{3}{*}{ M.S. Nasser et al } & 1-hexyl-3-methylimidazolium chloride & \multirow[t]{3}{*}{$10 \mathrm{mM}$} & \multirow[t]{3}{*}{11.74} & 13.26 \\
\hline & 1-butyl-3-methylimidazolium octyl-sulfate & & & 12.95 \\
\hline & 1-butyl-3-methylimidazolium bromide & & & 12.54 \\
\hline \multirow[t]{4}{*}{ Yanjun Ren et al } & 1-ethyl-3-methylimidazolium chloride & $0.5 \%$ & \multirow[t]{4}{*}{12.32} & 13.75 \\
\hline & 1-butyl-3-methylimidazolium chloride & $0.5 \%$ & & 14.25 \\
\hline & 1-hydroxyethyl-3-methylimidazolium chloride & $0.5 \%$ & & 14.25 \\
\hline & d1-aminoethyl-3-methylimidazolium & $0.5 \%$ & & 13.13 \\
\hline
\end{tabular}

Reinert et al. (2012) also studied the adsorption of pyridinium and imidazolium ionic liquids onto montmorillonite. Their characterization by X-ray diffraction confirmed that Na-montmorillonite is a potential adsorbent of ionic liquid's cations by the intercalation in the interlayer structure of montmorillonite. They concluded that pyridinium-based ionic liquids have more capacity to be adsorbed and thus changing the properties accordingly (Reinert et al. 2012).

Pei et al. (2019)'s study also comprised on investigating the adsorption capacity of imidazolium-based ionic liquids under different kinetic conditions. They uncovered that the cationic group of ionic liquids adsorbed onto the interlayer of Na-MMT altering its thermal stability and wettability. They also mentioned that the alteration in thermal stability of Na-MMT was strongly dependent upon the concentration of ionic liquids being used (Pei et al. 2019).

Nasser et al. (2016) reported intercalation of ionic liquids into bentonite. They studied the intercalation effect for 1-butyl-3-methylimidazolium octyl sulfate, 1-butyl3-methylimidazolium bromide, methylimidazolium chloride. They unearthed that the size, concentration and structure of ionic liquid used played a vital role in intercalation process (Nasser et al. 2016).

Wang et al. (2015) researched on the intercalation in montmorillonite. They chose 1-hexadecyl-3-methylimidazoliumchloridemonohydrate as an intercalated agent. They found out that with different amount of intercalated agent, different configurations would form. They also concluded that the interaction between ionic liquid and Na-MMT was pure electrostatic attraction in nature (Wang et al. 2015).

Luoa et al. (2017) while studying shale inhibition of ionic liquid-based mud performed XRD to see the cationic exchange between Ionic liquid and $\mathrm{Na}-\mathrm{Bt}$ layer. He confirmed that with change in concentration, the Na-Mt spacing increases. $0.2 \%$ showed more value than $0.05 \%$ but $0.5 \%$ showed lesser value than $0.2 \%$. This might be due to the change in configuration of cations (Luo et al. 2017a, b).

The following table summarized different authors' contribution involving various ionic liquids and their intercalation effect on Na-Bt observed by X-ray diffraction analysis. XRD helps to see the adsorption tendency of various ionic liquid into the $\mathrm{Na}$-Bt layer which In turn can improve or destroy the structure of $\mathrm{Na}-\mathrm{Bt}$ which as a result affect the rheology of the drilling fluid.

Table 2 presents XRD analysis conducted by various research groups using different ionic liquids to see the intercalation effect between Na-MMT and ionic liquid.

From Table 2, following postulates can be drawn:

- The d-spacing of dry $\mathrm{Na}-\mathrm{Bt}$ is mostly in the range of $11.5-13 \mathrm{~A}^{\circ}$

- The d-spacing of dry $\mathrm{Na}-\mathrm{Bt}$ modified with ionic liquid always increases showing successful intercalation between clay layers.

- From the work of Nasser et al. and Ren et al., it can be seen that ionic liquids having same anion but longer alkyl chain length will result into greater increase in d-spacing of clay which means the ionic liquid with longer alkyl chain will have more effect on Na-Bt dispersion as compared to smaller alkyl chain ionic liquids. 


\section{Conclusion}

1. Ionic liquid is a promising drilling fluid additive that is used in drilling fluid to enhance mud rheology.

2. Imidazolium-based ionic liquids have been the favorite class of researchers. However, protic ionic liquids also show remarkable thermal stability.

3. Longer alkyl chain will be more hydrophobic and less polar.

4. Smaller alkyl chain ionic may not expel water out from the alumino-silicate layers due to higher hydrophilicity.

5. The cationic exchange between ionic liquid and NaMMT expel water from Na-MMT layers and change the layer configuration after compressing it. This change in layer structure affects the swelling and dispersion properties of Na-Bt which changes its rheology.

6. A hydrophobic and polar ionic liquid is recommended as an ideal drilling fluid additive.

\section{Recommendation}

The alkyl chain being a cationic portion of ionic liquid affects the behavior of ionic liquids. A similar study must be conducted to see the role of anions in manipulating the behavior of ionic liquids as drilling fluid additives.

Funding I would like to vent my gratefulness to YAYASAN-UTP and Universiti Teknologi PETRONAS for providing resources and facilities to conduct this project.

\section{Declarations}

Conflict of interests The authors do not have any conflict of interests to declare.

Availability of data and material There is no supplementary data available for this review.

Open Access This article is licensed under a Creative Commons Attribution 4.0 International License, which permits use, sharing, adaptation, distribution and reproduction in any medium or format, as long as you give appropriate credit to the original author(s) and the source, provide a link to the Creative Commons licence, and indicate if changes were made. The images or other third party material in this article are included in the article's Creative Commons licence, unless indicated otherwise in a credit line to the material. If material is not included in the article's Creative Commons licence and your intended use is not permitted by statutory regulation or exceeds the permitted use, you will need to obtain permission directly from the copyright holder. To view a copy of this licence, visit http://creativecommons.org/licenses/by/4.0/.

\section{References}

Abbas MA, Zamir A, Elraies KA, Mahmood SM, Rasool MH (2021) A critical parametric review of polymers as shale inhibitors in water-based drilling fluids. J Pet Sci Eng. p 108745

Ahmed T, Makwashi N (2016) Effects of temperature and aging on bentonite and sepiolite drilling muds. Bridging the Gap Between Academia and Industry in Nigeria-Refocusing the Engineering p 174

Ahmed Khan R, Murtaza M, Abdulraheem A, Kamal MS, Mahmoud M (2020) Imidazolium-based ionic liquids as clay swelling inhibitors: mechanism, performance evaluation, and effect of different anions. ACS Omega 5(41):26682-26696

Allawi RH, Najem MA, Sagger MA, Abd SM (2019) Effect of temperature on drilling mud. In: Journal of physics: conference series, IOP Publishing

Anoop K, Sadr R, Yrac R, Amani M (2019) Viscosity measurement dataset for a water-based drilling mud-carbon nanotube suspension at high-pressure and high-temperature. Data Brief 24:103816

Barton CM (2014) Introduction to deepwater development. Wood group mustang/university of houston petroleum industry expert Lecture Series. October 29

Bavoh CB, Partoon B, Keong LK, Lal B, Wilfred C (2016) Effect of 1-Ethyl-3-methylimidazolium chloride and polyvinylpyrrolidone on kinetics of carbon dioxide hydrates. Int J Appl Chem 12(1):6-11

Bavoh CB, Ofei TN, Lal B, Sharif AM, Shahpin MHB, Sundramoorthy JD (2019) Assessing the impact of an ionic liquid on $\mathrm{NaCl} / \mathrm{KCl} /$ polymer water-based mud (WBM) for drilling gas hydrate-bearing sediments. J Mol Liq 294:111643

Bogdanov MG, Svinyarov I, Kunkel H, Steinle C, Arkhipova M, Kantlehner W, Maas G (2010) Empirical polarity parameters for hexaalkylguanidinium-based room-temperature ionic liquids. Zeitschrift Für Naturforschung B 65(7):791-797

Caenn R, Darley HC, Gray GR (2011) Composition and properties of drilling and completion fluids, Gulf professional publishing

Chilingarian GV, Alp E, Caenn R, Al-Salem M, Uslu S, Gonzales S, Dorovi RJ, Mathur R, Yen TF (1986) Drilling fluid evaluation using yield point-plastic viscosity correlation. Energy Sources 8(2-3):233-244

Coussot P (2017) Mudflow rheology and dynamics. Routledge

Datt C, Zhu L, Elfring GJ, Pak OS (2015) Squirming through shearthinning fluids. J Fluid Mech. $\mathbf{7 8 4}$

Dong Y, Li H, Fan Y, Ma X, Sun D, Wang Y, Gao Z, Dong X (2020) Tunable dewatering behavior of montmorillonite suspension by adjusting solution $\mathrm{pH}$ and electrolyte concentration. Minerals 10(4):293

Dreus AY, Sudakov A, Kozhevnikov A, Vakhalin YN (2016) Study on thermal strength reduction of rock formation in the diamond core drilling process using pulse flushing mode. Sci Bull Natl Min Univ 3:5-10

Ekeinde EB, Okoro EE, Dosunmu A, Iyuke S (2019) Optimizing aqueous drilling mud system viscosity with green additives. J Pet Explor Prod Technol 9(1):315-318

Elmquist SA, Boesger LE (1987) Drilling mud cleaning system, Google Patents

Fukaya Y, Ohno H (2013) Hydrophobic and polar ionic liquids. Phys Chem Chem Phys 15(11):4066-4072

Guangchang M (2004) Air Drilling Technology and Its Application. Drill Prod Technol 27(3; NUMB 120):4-8

Halliday WS, Thielen VM (1987) Drilling mud additive, Google Patents

Hamed SB, Belhadri M (2009) Rheological properties of biopolymers drilling fluids. J Petrol Sci Eng 67(3-4):84-90

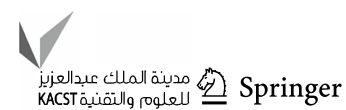


Hayes R, Imberti S, Warr GG, Atkin R (2014) Effect of cation alkyl chain length and anion type on protic ionic liquid nanostructure. J Phys Chem C 118(25):13998-14008

Herzhaft B, Peysson Y, Isambourg P, Delepoulle A, Abdoulaye T (2001) Rheological properties of drilling muds in deep offshore conditions. In: SPE/IADC drilling conference, society of petroleum engineers

Hong SH, Jo HJ, Choi M-J, Jang HW, Kim YJ, Hwang WR, Kim SY (2019) Influence of MoS2 Nanosheet Size on Performance of Drilling Mud. Polymers 11(2):321

Huaike GJYJL, Xuebin ZSLHL (2010) Synthetic-based drilling fluid with constant-rheology used in deepwater drilling. Pet Drill Tech. 2

Huddleston JG, Visser AE, Reichert WM, Willauer HD, Broker GA, Rogers RD (2001) Characterization and comparison of hydrophilic and hydrophobic room temperature ionic liquids incorporating the imidazolium cation. Green Chem 3(4):156-164

Kjøsnes I, Løklingholm G, Saasen A, Syrstad S, Agle A, Solvang K-A (2003) Successful water based drilling fluid design for optimizing hole cleaning and hole stability. In: SPE/IADC Middle East drilling technology conference and exhibition, society of petroleum engineers

Kulkarni SD, Sieverling JM, Jamison DE (2019) Shear thinning calibration fluids for rheometers and related methods, Google Patents

Kurnia KA, Neves CM, Freire MG, Santos LM, Coutinho JA (2015) Comprehensive study on the impact of the cation alkyl side chain length on the solubility of water in ionic liquids. J Mol Liq 210:264-271

Lee J-M, Prausnitz JM (2010) Polarity and hydrogen-bond-donor strength for some ionic liquids: effect of alkyl chain length on the pyrrolidinium cation. Chem Phys Lett 492(1-3):55-59

Luo Z, Pei J, Wang L, Yu P, Chen Z (2017a) Influence of an ionic liquid on rheological and filtration properties of water-based drilling fluids at high temperatures. Appl Clay Sci 136:96-102

Luo Z, Wang L, Yu P, Chen Z (2017b) Experimental study on the application of an ionic liquid as a shale inhibitor and inhibitive mechanism. Appl Clay Sci 150:267-274

Morenov V, Leusheva E (2017) Development of drilling mud solution for drilling in hard rocks. Int J Eng Trans A 30(4):620-626

Nasser M, Onaizi SA, Hussein I, Saad M, Al-Marri M, Benamor A (2016) Intercalation of ionic liquids into bentonite: Swelling and rheological behaviors. Colloids Surf A 507:141-151

Ofei TN, Bavoh CB, Rashidi AB (2017) Insight into ionic liquid as potential drilling mud additive for high temperature wells. J Mol Liq 242:931-939

Okon AN, Agwu OE, Udoh FD (2015) Evaluation of the cuttings carrying capacity of a formulated synthetic-based drilling Mud. In: SPE Nigeria annual international conference and exhibition, society of petroleum engineers

Okrajni S, Azar J (1986) The effects of mud rheology on annular hole cleaning in directional wells. SPE Drill Eng 1(04):297-308

Patel AD, Thaemlitz CJ, McLaurine HC, Stamatakis E (1999) Drilling fluid additive and method for inhibiting hydration, Google Patents

Patel A, Stamatakis S, Young S, Friedheim J (2007) Advances in inhibitive water-based drilling fluids - can they replace oil-based muds? In: International symposium on oilfield chemistry, society of petroleum engineers
Patel AD (2001) Oil-based drilling fluid, Google Patents

Pei J, Xing X, Xia B, Wang Z, Luo Z (2019) Study on the Adsorption Behavior between an Imidazolium Ionic Liquid and Na-Montmorillonite. Molecules 24(7):1396

Phan-Thien N, Mai-Duy N (2017) Understanding viscoelasticity: an introduction to rheology. Springer, Berlin

Rasool MH, Zamir A, Elraies KA, Ahmad M, Ayoub M, Abbas MA (2021) Investigative review on cutting transportation ability of ionic liquid-based drilling mud. J Hunan Univ Nat Sci. 48(2)

Rasool MH, Zamir A, Elraies KA, Ahmad M, Ayoub M, Abbas MA (2021) Potassium carbonate based deep eutectic solvent (DES) as a potential drilling fluid additive in deep water drilling applications. Pet Sci Technol. pp 1-20

Reinert L, Batouche K, Lévêque J-M, Muller F, Bény J-M, Kebabi B, Duclaux L (2012) Adsorption of imidazolium and pyridinium ionic liquids onto montmorillonite: characterisation and thermodynamic calculations. Chem Eng J 209:13-19

Ren Y, Wang H, Ren Z, Zhang Y, Geng Y, Wu L, Pu X (2019) Adsorption of imidazolium-based ionic liquid on sodium bentonite and its effects on rheological and swelling behaviors. Appl Clay Sci 182:105248

Rocha LAS, Junqueira P, Roque J (2003) Overcoming deep and ultra deepwater drilling challenges. In: Offshore technology conference

Saikia T, Mahto V (2016) Evaluation of 1-Decyl-3-Methylimidazolium Tetrafluoroborate as clathrate hydrate crystal inhibitor in drilling fluid. J Nat Gas Sci Eng 36:906-915

Singh SK, Savoy AW (2020) Ionic liquids synthesis and applications: an overview. J Mol Liq 297:112038

Van Slyke DC (1994) White mineral oil-based drilling fluid, Google Patents

Srivatsa JT, Ziaja MB (2011) An experimental investigation on use of nanoparticles as fluid loss additives in a surfactant-polymer based drilling fluids. In: international petroleum technology conference

Voelkel A, Szymanowski J, Beger J, Rüstig H (1988) Measurement of the polarity of alkyl derivatives of diazapolyoxyethylene ethers by gas chromatography. J Chromatogr A 454:51-63

Wang X, Liu B, Yu P (2015) Research on the preparation and mechanism of the organic montmorillonite and its application in drilling fluid. J Nanomater 2015:4

Welahettige P, Lie B, Vaagsaether K (2019) Computational fluid dynamics study of shear thinning fluid (drilling fluid) viscosity models in an open venturi channel. Int J Pet Sci Technol 13(1):9-20

Welton T (2018) Ionic liquids: a brief history. Biophys Rev 10(3):691-706

Yang L, Yang X, Wang T, Jiang G, Luckham PF, Li X, Shi H, Luo J (2019) Effect of alkyl chain length on shale hydration inhibitive performance of vinylimidazolium-based ionic liquids. Ind Eng Chem Res 58(20):8565-8577

Publisher's Note Springer Nature remains neutral with regard to jurisdictional claims in published maps and institutional affiliations. 